\title{
Enteric-coated, highly standardized cranberry extract reduces risk of UTls and urinary symptoms during radiotherapy for prostate carcinoma
}

This article was published in the following Dove Press journal:

Cancer Management and Research

23 August 2012

Number of times this article has been viewed

\author{
Alberto Bonetta' \\ Francesco Di Pierro² \\ 'Unità Operativa Radioterapia \\ Oncologica, Istituti Ospedalieri di \\ Cremona, Cremona; ${ }^{2}$ Velleja Research, \\ Milan, Italy
}

Background: Cranberry (Vaccinium macrocarpon) proanthocyanidins can interfere with adhesion of bacteria to uroepithelial cells, potentially preventing lower urinary tract infections (LUTIs). Because LUTIs are a common side effect of external beam radiotherapy (EBRT) for prostate cancer, we evaluated the clinical efficacy of enteric-coated tablets containing highly standardized V. msacrocarpon (ecVM) in this condition.

Methods: A total of 370 consecutive patients were entered into this study. All patients received intensity-modulated radiotherapy for prostate cancer; 184 patients were also treated with ecVM while 186 served as controls. Cranberry extract therapy started on the simulation day, at which time a bladder catheterization was performed. During EBRT (over 6-7 weeks), all patients underwent weekly examination for urinary tract symptoms, including regular urine cultures during the treatment period.

Results: Compliance was excellent, with no adverse effects or allergic reactions being observed, apart from gastric pain in two patients. In the cranberry cohort $(n=184), 16$ LUTIs $(8.7 \%)$ were observed, while in the control group $(n=186) 45$ LUTIs $(24.2 \%)$ were recorded. This difference was statistically significant. Furthermore, lower rates of nocturia, urgency, micturition frequency, and dysuria were observed in the group that received cranberry extract.

Conclusion: Cranberry extracts have been reported to reduce the incidence of LUTIs significantly in women and children. Our data extend these results to patients with prostate cancer undergoing irradiation to the pelvis, who had a significant reduction in LUTIs compared with controls. These results were accompanied by a statistically significant reduction in urinary tract symptoms (dysuria, nocturia, urinary frequency, urgency), suggesting a generally protective effect of cranberry extract on the bladder mucosa.

Keywords: urinary tract infection, cranberry, radiotherapy, prostate cancer

\section{Introduction}

Vaccinium macrocarpon (cranberry) is a shrub native to the US. Its berries have a long tradition of use both as a food and as a medicine, especially for the treatment of urinary tract infections. ${ }^{1}$ The active ingredients of $V$. macrocarpon are believed to be complex proanthocyanidins with an A-type interflavane bond. In the past two decades, interest in the cranberry has been rekindled by demonstration of the clinical efficacy of cranberry preparations (juice, extracts) in several preventive studies in patients with lower urinary tract infections (LUTIs). ${ }^{2}$ This large body of documentation was observed in women suffering from recurrent cystitis, but preliminary data from patients suffering from other pelvic conditions, eg, neuropathic bladder, were also reported. ${ }^{3-16}$ Cranberry extracts decrease adhesion of bacteria to uroepithelial cells,
Correspondence: Francesco Di Pierro Velleja Research,Viale Lunigiana 23, 20I25, Milano, Italy

$\mathrm{Tel}+393495527663$

Fax +3905 235। 1894

Email f.dipierro@vellejaresearch.com 
limiting colonization of bladder cells. ${ }^{17-23}$ Because LUTI is one of the frequent adverse events possible during external beam radiotherapy (EBRT) to the pelvis, we wondered if $V$. macrocarpon, as a standardized extract in an enteric-coated formulation (ecVm), could prevent LUTIs and moderate the bladder irritation associated with this treatment. Of relevance for this condition, cranberry proanthocyanidins show antiproliferative activity. ${ }^{24-27}$

\section{Materials and methods}

Enrolment of subjects took place between July 6, 2007 and September 3, 2010 at the Unità Operativa di Radioterapia Oncologica of Cremona Hospital (Cremona, Italy). After obtaining approval from our local ethics board, we conducted this study in the field of routine clinical practice, following international guidelines and in line with the principles outlined in the Declaration of Helsinki. This nonrandomized study was carried out at a single center in Italy where experimental protocols on nutraceutical products do not require ethical approval. Patients with prostatic adenocarcinoma $(n=370)$ were treated with radiotherapy to the prostatic area (and to the pelvis if the risk of lymph node involvement was higher than $15 \%$ according to Kattan's nomograms [a prediction tool designed by Flern and Kattan, Memorial Sloane Kettering Cancer Center, NY, www.mskcc.org/nomograms/prostate]). Only patients treated with radical, adjuvant, or salvage radiotherapy were entered into the study. Patients with a history of pelvic EBRT, previous pelvic malignancy, a Karnofsky score $<80$, renal failure, or refusing treatment with cranberry extract were excluded from the study. In total, 186 of 370 patients had undergone surgery. Patients were sorted into two groups, ie, one treated with ecVm $(n=184)$ and the other serving as controls $(n=186)$. None of the patients had symptoms of cystitis at the time of enrolment, so no urine culture was carried out at this time.

Radiotherapy was performed using $6 \mathrm{MV}$ photon beam of Linac with intensity-modulated radiation therapy techniques (years 2007-2009 step and shoot; 2009-2010 rapid arc therapy). A hypofractionated schedule with simultaneous integrated boosting was used, ie, 2.3 Gy for the fraction on the prostatic bed or prostate, 2.1 Gy on seminal vesicles or their postoperative bed, and 1.7-1.75 Gy on lymph node stations (when treated). Treatments lasted for 6-7 weeks, with administration of total doses of 66.7 Gy (adjuvant therapy), 69 Gy (salvage therapy), or 73.6 Gy (radical therapy). During planning of treatment, bladder volume and average dose to the whole bladder (V50 and V60) were recorded to assess the impact of EBRT on urinary symptoms.
One enteric-coated tablet per day $\left(\mathrm{VO} 370^{\circledR}\right.$ or Monoselect Macrocarpon ${ }^{\circledR}$, PharmExtracta, Pontenure, Italy), containing $200 \mathrm{mg}$ of a highly standardized cranberry extract titered as $30 \%$ proanthocyanidins according to the methods of the European Pharmacopoeia, was used for preventive therapy. Compared with cranberry juice and cranberry juice powder, the purified extract does not contain significant amounts of free sugars and does not affect glycemia. Enteric coating was chosen to prevent possible degradation of proanthocyanidines during processing, potential instability in gastric juices, and possible interaction with gastric Helicobacter pylori. ${ }^{28,29}$ No particular suggestion was given to patients in terms of diet, except to take the product without food.

During treatment (6-7 weeks), all patients underwent weekly examination to assess urinary symptoms (mean weekly urinary frequency, dysuria, nocturia, urgency) and consumption of nonsteroidal anti-inflammatory therapy. These symptoms, especially urinary frequency, are due to the inflammatory process, both actinic and infective, and their intensity often reflects the radiation dose given. Two urine cultures were performed at weeks 3 and 6 of treatment, and a further culture was performed if intense dysuria was present. Urinary tract infection was assumed when the findings of bacteriuria exceeded 100,000 U/mL, accompanied by specific symptoms of cystitis.

\section{Statistical analysis}

Pearson's Chi-square test was used to analyze most of the parameters. Some analytical checks were adjusted using the Cochran-Mantel-Haenszel test due to some patients having diabetes. A Wilcoxon test for independent groups was used for some parameters (eg, urgency), and both the Student's $t$-test and Wilcoxon test were used for others (eg, bladder volume).

\section{Results}

Compliance in the ecVm treatment group was excellent, with only one patient discontinuing treatment for 10 days during the study. All patients completed their planned EBRT. Acute bladder toxicity led to brief discontinuation of treatment in one case. Two patients in the ecVm group, affected by chronic gastritis, complained of gastric pain, which required use of a protecting agent, but no other unwanted effects or allergies were observed.

Of the controls, 45 of 186 patients $(24.2 \%)$ suffered LUTIs. Recurrent infection was seen in eight patients $(4.3 \%)$, while urinary infections with no recurrence were detected in 16 of 184 patients $(8.7 \%)$ treated with ecVm 
(odds ratio 2.78 for LUTI). These data were confirmed when the presence of diabetes was considered (CochranMantel-Haenszel test). Table 1 shows the frequency and types of bacteria found in the urine cultures. As expected, Escherichia coli and bacteria of enteric origin were the most common, with a higher prevalence of coliform bacteria in controls (21 cases, with a further case of mixed Enterobacter/E. coli infection versus five cases in the ecVm group). Of the eight relapses observed in the control group, five were caused by E. coli, two by enterococci, and one by a hemolytic staphylococcal strain. Analysis of urinary symptomatology was carried out in all but two (namely 368) patients, independent of the presence of an infectious process. These two patients from the control group with catheterization were excluded from this evaluation due to absence of bladder perception which required them to empty their bladders at fixed times. The following parameters were included in the analysis of the degree of bladder toxicity to bladder average volume, average dosage to the whole organ, and proportion of the organ included in the $50 \mathrm{~Gy}$ (V50) and 60 Gy (V60) isodoses, respectively (Table 2). No statistically significant difference between the ecVM and the control group could be confirmed according to Student's or Wilcoxon analysis ( $t=0.2597$ and $P=0.3106$, respectively). A lower incidence of dysuria, assessed by the Boyarsky scale (Table 3), was noticed in the treatment group, with symptoms being generally milder than in the control group. Thus, absence of symptoms (G0) was observed in $62 \%$ of patients in the treatment group, but only in $36 \%$ of controls. A similar trend was observed for the other degrees of dysuria (G1, occasional burning; G2, frequent burning; $\mathrm{G} 3$, constant pain), which was significantly higher in the control group $(P<0.0001$, Table 4$)$. A lower incidence of dysuria (G2-3) was also seen in assessment of patients with LUTI (treated group 3/10 versus control 14/25).

On the whole, the urinary symptoms due to radiotherapy were milder in the treatment group than in controls, with statistically significant differences in terms of nocturia $(31 \%$ versus 54\% increase, $P<0.001)$, urgency $(31 \%$ versus $54 \%$ increase, $P<0.0001$ ), and urine flow (14\% versus $21.5 \%$ decrease, $P=0.0066)$, as well as higher average daily urination frequency, that increased from 5.33 to 8.74 in the control group, but from 5.85 to only 7.55 in the treatment group (Table 5, $P=0.0006$ ).

\section{Discussion}

With an average incidence ranging between $0.5 \%$ and $1 \%$ of the population, bacterial cystitis is undoubtedly one of the most frequent infections in humans. The frequency of cystitis increases with advancing age, and is favored by a host of factors, including functional or anatomic alterations in the urinary tract, congenital malformations, prostate disorders, bladder surgery, urinary incontinence, catheterization, hindered urinary outflow, presence of bladder stones, diabetes, acquired immune deficiency syndrome, and bone marrow lesions. Approximately $90 \%$ of bladder infections are caused by Gram-negative bacteria, with a clear prevalence of germs of fecal origin. More than half of urinary infections are caused by E. coli, with contributions from Enterococcus fecalis, Pseudomonas aeruginosa, Enterobacter cloacae, Klebsiella pneumoniae, and Proteus mirabilis being less frequent. ${ }^{30-32}$ Notwithstanding the use of antibiotics, LUTIs are plagued by a high frequency of relapse (20\%), especially in certain populations, including menopausal women, where the short length of the urethra combines with unfavorable changes in the vaginal microenvironment caused by decreased estrogen. ${ }^{30}$

Table I Frequency and type of urinary infections in the treatment and control groups

\begin{tabular}{|c|c|c|c|c|}
\hline \multirow[t]{2}{*}{ Bacterium } & \multicolumn{2}{|l|}{ Treatment group } & \multicolumn{2}{|l|}{ Control group } \\
\hline & Absolute number & $\begin{array}{l}\text { Percentage with } \\
\text { infections }\end{array}$ & Absolute number & $\begin{array}{l}\text { Percentage with } \\
\text { infections }\end{array}$ \\
\hline Escherichia coli & 5 & $30 \%$ & 21 & $60 \%$ \\
\hline Enterococcus faecalis & 6 & $40 \%$ & 10 & $8 \%$ \\
\hline Enterobacter cloacae $+E$. coli & 0 & & I & 0 \\
\hline Enterobacter cloacae & 2 & $10 \%$ & 2 & $4 \%$ \\
\hline Pseudomonas aeruginosa & I & $10 \%$ & 2 & $8 \%$ \\
\hline Streptococcus agalactiae & 2 & $10 \%$ & - & - \\
\hline Staphylococcus epidermidis & - & - & I & $4 \%$ \\
\hline Staphylococcus emolitico & - & - & I & $4 \%$ \\
\hline Klebsiella pneumoniae & - & - & I & $4 \%$ \\
\hline Proteus mirabilis & - & - & 3 & $4 \%$ \\
\hline Not known/mixed & - & - & 3 & $4 \%$ \\
\hline Total & 16 & $100 \%$ & 45 & $100 \%$ \\
\hline
\end{tabular}


Table 2 Bladder volume for radiation dose (using dose/volume histograms) in the group treated with cranberry extract and controls

\begin{tabular}{lll}
\hline Absolute value & Treated with cranberry extract & Controls \\
\hline Average V50 & 24.4 & 26.0 \\
Average V60 & 13.0 & 14.2 \\
\hline
\end{tabular}

Notes: $P=0.2597$ (Student's $t$-test) and $P=0.3106$ (Wilcoxon's test).

Another population at increased risk of urinary infections is patients with cancer treated using pelvic radiotherapy, with an incidence ranging from $14 \%$ to $33 \%$, depending on the type of cancer and radiation technique used. ${ }^{33-36}$ Consumption of cranberry juice and its extracts has been related to a decreased incidence of LUTIs. ${ }^{2}$ The mechanism of this effect has been widely debated but is still largely unknown. The older belief that acidification of urine underlies this action has been dispelled, mainly because of the observation that several bacterial strains sensitive to the action of cranberry extract actually develop well at low $\mathrm{pH}$ values. The activity of cranberry products has been consistently associated with their procyanidin content but, given that these compounds are not absorbed to a significant extent, a direct action seems unlikely, and various alternative theories have been proposed, including stimulation of secretion of an hitherto unidentified endogenous antibacterial agent. ${ }^{37}$ In in-vitro assays, cranberry procyanidins can significantly inhibit adhesion of pathogenic bacteria to the mucous membrane, preventing progression of infection. ${ }^{38-41}$ Without adhesion, bacteria cannot proliferate in the urinary tract and are eventually excreted. Inhibition of bacterial adhesion to the bladder wall has, in turn, been related to dose-dependent inhibition of specific structurally complementary carbohydrates on the surface of membranes and mucous cells. ${ }^{1,2,17,18,20,23}$ After intake of cranberry-based products, only procyanidin A2, a dimeric compound, has been detected in urine, while higher oligomers do not appear to be absorbed at all. Nevertheless, antiadhesive properties are maintained in the urine, ${ }^{42}$ an action that would be difficult to trace to the presence of procyanidin A2 alone.

The results of this study demonstrate that the beneficial effects of cranberry extract in prevention of LUTIs can be

Table 3 Description of dysuria discomfort scale: grading extract from Boyarsky score

\begin{tabular}{ll}
\hline Degree & Description \\
\hline 0 & No symptoms \\
1 & Burning sensation during urination \\
2 & $\begin{array}{l}\text { Frequent burning or pain during urination, more than } 50 \% \\
\text { of times }\end{array}$ \\
3 & Continuous burning sensation or pain during urination \\
\hline
\end{tabular}

Table 4 Difference in distribution of incidence of dysuria $(P<0.000 \mathrm{I})$

\begin{tabular}{lll}
\hline Dysuria & Treated & Control \\
\hline Degree 0 & II4 (6I.9\%) & $66(35.9 \%)$ \\
Degree I & $49(26.6 \%)$ & $60(32.6 \%)$ \\
Degree 2 & $20(10.9 \%)$ & $44(23.9 \%)$ \\
Degree 3 & $1(0.6 \%)$ & $14(7.6 \%)$ \\
All & 184 & 184 \\
\hline
\end{tabular}

observed also in nonphysiologic situations, such as the acute bladder damage associated with high-dose irradiation. Pelvic radiotherapy is well known to induce inflammatory damage to and partial de-epithelization of the bladder mucosa, easily triggering bacterial infections and decreasing compliance with treatment. The data on coliform bacteria infecting $5 / 184$ patients in the treatment group and 21/186 patients in the control group seems to be of special relevance, and an even more statistically significant result is observed when recurrent infections are also considered. Therefore, it seems surprising that use of cranberry extract in supportive care cancer had been largely overlooked in the clinical literature, with only two studies having been reported. The first was by Cowan et $\mathrm{al},{ }^{43}$ and was a placebocontrolled, double-blind study conducted in 128 female patients treated with radiotherapy or a combination of radiotherapy and chemotherapy for uterine cancer, with only a tendency towards reduction of the frequency of LUTI observed in the treatment group ( $82.5 \%$ versus $89.3 \%$ in the placebo group), with the difference failing to reach statistical significance. A limitation of that study was the use of cranberry juice as a nonstandardized preparation, so it is therefore unclear what dosage of proanthocyanidin was actually administered, the optimal dosage of which appears to be $36 \mathrm{mg} /$ day. ${ }^{44} \mathrm{~A}$ second limitation was the reduced compliance observed in the treatment group, due to poor palatability of the cranberry juice, the strong acidity of which is generally buffered by addition of sugar.

The second study by Campbell et al also used cranberry juice for prevention (or at least attenuation) of bladder symptoms in patients undergoing pelvic radiotherapy, and had a negative outcome, ${ }^{45}$ with no significant difference observed between the cranberry-treated group and controls. In this study, the endpoint did not include the incidence of urinary infections, with only urinary symptoms being considered, and the 120 patients enrolled were randomly sorted into two equivalent groups treated with cranberry juice or apple juice. In addition to having the drawbacks discussed by Cowan et al, use of apple juice, which contains significant amounts of polyphenols, seems questionable. These design limitations were addressed in our study by using an enteric-coated and highly standardized 
Table 5 Description of increase in mean urinary frequency (number of daily urinations per week, $P=0.0006$ )

\begin{tabular}{llll}
\hline & Mean frequency before EBRT & Mean frequency, peak during EBRT & Increase (\%) \\
\hline Group treated with cranberry extract & 5.85 & 7.55 & $+29 \%$ \\
Control group & 5.33 & 8.74 & $+63 \%$ \\
\hline
\end{tabular}

Abbreviation: EBRT, external beam radiotherapy.

cranberry extract and including a combination of objective (LUTI) and subjective (urinary discomfort) endpoints.

There were several reasons for using an enteric-coated cranberry extract. Proanthocyanidins are polyphenols and, as such, are strongly antioxidant. Like all antioxidants, they are rather unstable during processing and storage. ${ }^{28}$ Moreover, proanthocyanidins do interact with bacteria that colonize the stomach, like H. pylori. ${ }^{29}$ The possible presence of this strain in the stomachs of patients promptly reduces the proanthocyanidin content available to counteract $E$. coli and other colonic pathogen bacteria in the gut. Enteric coating provides a solution to these potential problems. Therefore, enteric coating protects the active agents from environmental instability and prevents dissolution, but at $\mathrm{pH}$ values of about 6.0-6.8, as found in the duodenum, solving the potential problem created by the possible presence of $H$. pylori. Last, but not least, enteric coating also minimizes loss of proanthocyanidins as a result of possible binding with proline-rich proteins in saliva and with biologic membranes on portions of enteric mucosa where proanthocyanidins are not absorbed in significant amounts. ${ }^{46}$

Despite the lack of randomization in this study, a clear-cut reduction in the LUTIs and bladder discomfort associated with pelvic irradiation was observed, with statistically significant differences in terms of dysuria, nocturia, and urinary frequency. It is possible that, because of its strong antioxidant properties, cranberry could attenuate actinic damage to the bladder mucosa, reducing the inflammatory process and, as a consequence, its symptoms. Full evaluation of this issue will require a further ad hoc study.

\section{Acknowledgment}

The authors thank Giovanni Appendino for reviewing the manuscript and Martino Recchia for statistical data processing.

\section{Disclosure}

The authors do not receive any kind of payment for writing this paper or in relationship with the issues described in the article.

\section{References}

1. Capasso F, Grandolini G, Izzo AA. Piante medicinali e sistema urinario. Mirtillo americano. In: Fitoterapia. Impiego Razionale delle Droghe Vegetali. [Phytotherapy, Rationale Use of Drugs From The Plant Kingdom]. Berlin, Germany: Springer-Verlag; 2006. Italian.
2. Jepson RG, Craig JC. Cranberries for preventing urinary tract infections Cochrane Database Syst Rev. 2008;23(1):CD001321.

3. Jepson RG, Craig JC. A systematic review of the evidence for cranberries and blueberries in UTI prevention. Mol Nutr Food Res. 2007;51(6):738-745.

4. Lavigne JP, Bourg G, Botto H, Sotto A. Cranberry (Vaccinium macrocarpon) and urinary tract infections: study model and review of literature. Pathol Biol. 2007;55(8-9):460-464.

5. McMurdo ME, Argo I, Phillips G, Daly F, Davey PJ. Cranberry or trimethoprim for the prevention of recurrent urinary tract infections? A randomized controlled trial in older women. Antimicrob Chemother. 2009;63(2):389-395.

6. Pérez-López FR, Haya J, Chedraui P. Vaccinium macrocarpon: an interesting option for women with recurrent urinary tract infections and other health benefits. J Obstet Gynaecol Res. 2009;35(4):630-639.

7. Wing DA, Rumney PJ, Preslicka CW, Chung JH. Daily cranberry juice for the prevention of asymptomatic bacteriuria in pregnancy: a randomized, controlled pilot study. J Urol. 2008;180(4):1367-1372.

8. Lynch MD. Cranberry for prevention of urinary tract infections. Am Fam Physician. 2004;70(11):2175-2177.

9. Linsenmeyer TA, Harrison B, Oakley A, Kirshblum S, Stock JA, Millis SR. Evaluation of cranberry supplement for reduction of urinary tract infections in individuals with neurogenic bladder secondary to spinal cord injury. A prospective, double blinded, placebo controlled, crossover study. J Spinal Cord Med. 2004;27(1):29-34.

10. Bailey DT, Dalton C, Joseph Daugherty F, Tempesta MS. Can a concentrated cranberry extract prevent recurrent urinary tract infections in women? A pilot study. Phytomedicine. 2007;14(4):237-241.

11. Hess MJ, Hess PE, Sullivan MR, Nee M, Yalla SV. Evaluation of cranberry tablets for the prevention of urinary tract infections in spinal cord injured patients with neurogenic bladder. Spinal Cord. 2008;46(9):622-626.

12. Head KA. Natural approaches to prevention and treatment of infections of the lower urinary tract. Altern Med Rev. 2008;13(3):227-244.

13. Sumukadas D, Davey P, McMurdo ME. Recurrent urinary tract infections in older people: the role of cranberry products. Age Ageing. 2009;38(3):255-257.

14. Cimolai N, Cimolai T. The cranberry and the urinary tract. Eur J Clin Microbiol Infect Dis. 2007;26(11):767-776.

15. Santillo VM, Lowe FC. Cranberry juice for the prevention and treatment of urinary tract infections. Drugs Today. 2007;43(1):47-54.

16. Masson P, Matheson S, Webster AC, Craig JC. Meta-analyses in prevention and treatment of urinary tract infections. Infect Dis Clin N Am. 2009;23:355-385.

17. Eydelnant IA, Tufenkji N. Cranberry derived proanthocyanidins reduce bacterial adhesion to selected biomaterials. Langmuir. 2008;24(18): 10273-10281.

18. Liu Y, Gallardo-Moreno AM, Pinzon-Arango PA, Reynolds Y, Rodriguez G, Camesano TA. Cranberry changes the physicochemical surface properties of E. coli and adhesion with uroepithelial cells. Colloids Surf B Biointerfaces. 2008;65(1):35-42.

19. Pinzón-Arango PA, Liu Y, Camesano TA. Role of cranberry on bacterial adhesion forces and implications for Escherichia coli-uroepithelial cell attachment. J Med Food. 2009;12(2):259-270.

20. Gupta K, Chou MY, Howell A, Wobbe C, Grady R, Stapleton AE. Cranberry products inhibit adherence of p-fimbriated Escherichia coli to primary cultured bladder and vaginal epithelial cells. J Urol. 2007; 177(6):2357-2360. 
21. Howell AB. Bioactive compounds in cranberries and their role in prevention of urinary tract infections. Mol Nutr Food Res. 2007;51(6): $732-737$.

22. Guay DR. Cranberry and urinary tract infections. Drugs. 2009;69(7): 775-807.

23. Lavigne JP, Bourg G, Combescure C, Botto H, Sotto A. In-vitro and in-vivo evidence of dose-dependent decrease of uropathogenic Escherichia coli virulence after consumption of commercial Vaccinium macrocarpon (cranberry) capsules. Clin Microbiol Infect. 2008;14(4):350-355.

24. He X, Liu RH. Cranberry phytochemicals: isolation, structure elucidation, and their antiproliferative and antioxidant activities. J Agric Food Chem. 2006;54(19):7069-7074.

25 . Neto CC. Cranberry and its phytochemicals: a review of in vitro anticancer studies. J Nutr. 2007;137(Suppl 1):186S-193S.

26. Neto CC, Amoroso JW, Liberty AM. Anticancer activities of cranberry phytochemicals: an update. Mol Nutr Food Res. 2008;52 Suppl 1: S18-S27.

27. Prasain JK, Jones K, Moore R, et al. Effect of cranberry juice concentrate on chemically-induced urinary bladder cancers. Oncol Rep. 2008;19(6):1565-1570.

28. Pappas E, Schaich KM. Phytochemicals of cranberries and cranberry products: characterization, potential health effects, and processing stability. Crit Rev Food Sci Nutr. 2009;49(9):741-781.

29. Matsushima M, Suzuki T, Masui A, et al. Growth inhibitory action of cranberry on Helicobacter pylori. J Gastroenterol Hepatol. 2008; 23 Suppl 2:S175-S180.

30. Hooton TM, Stamm WE. Diagnosis and treatment of uncomplicated urinary tract infection. Infect Dis Clin North Am. 1997;11(3):551-581.

31. Anderson RU. Management of lower urinary tract infections and cystitis. Urol Clin North Am. 1999;26(4):729-735.

32. Alukal J, Mir J, Bergin C. Genitourinary infection. In: Handbook of Urology. 3rd ed. Philadelphia, PA: Lippincott Williams and Wilkins; 2004.

33. Prasad KN, Pradhan S, Datta NR. Urinary tract infection in patients of gynecological malignancies undergoing external pelvic radiotherapy. Gynecol Oncol. 1995;57(3):380-382.

34. Roberts FJ, Murphy J, Ludgate C. The value and significance of routine urine cultures in patients referred for radiation therapy of prostatic malignancy. Clin Oncol. 1990;2(1):18-21.

35. Bialas I, Bessell EM, Sokal M, Slack R. A prospective study of urinary tract infection during pelvic radiotherapy. Radiother Oncol. 1989;16(4):305-309.
36. Bessell EM, Granville-White M. The effect of prophylactic trimethoprim on aerobic urinary tract infection during pelvic radiotherapy and the incidence of infections due to fastidious or anaerobic organisms. Clin Oncol. 1994;6(2):116-120.

37. Johnson BJ, Lin B, Rubin RA, Malanoski AP. Media acidification by Escherichia coli in the presence of cranberry juice. BMC Res Notes. 2009;2:226

38. Zafriri D, Ofek I, Adar R, Pocino M, Sharon N. Inhibitory activity of cranberry juice on adherence of type 1 and type p-fimbriated Escherichia coli to eukaryotic cells. Antimicrob Agents Chemother. 1989;33(1):92-98.

39. Viskelis P, Rubinskiene M, Jasutiene I, Sarkinas A, Daubaras R, Cesoniene L. Anthocyanins, antioxidative, and antimicrobial properties of American cranberry (Vaccinium macrocarpon Ait.) and their press cakes. J Food Sci. 2009;74(2):C157-C161.

40. Vinson JA, Bose P, Proch J, Al Kharrat H, Samman N. Cranberries and cranberry products: powerful in vitro, ex vivo, and in vivo sources of antioxidants. J Agric Food Chem. 2008;56(14):5884-5891.

41. Johnson BJ, Lin B, Dinderman MA, Rubin RA, Malanoski AP, Ligler FS. Impact of cranberry on Escherichia coli cellular surface characteristics. Biochem Biophys Res Commun. 2008;377(3):992-994.

42. Tempera G, Corsello S, Genovese C, Caruso FE, Nicolosi D. Inhibitory activity of cranberry extract on the bacterial adhesiveness in the urine of women: an ex-vivo study. Int J Immunopathol Pharmacol. 2010;23: 611-618.

43. Cowan CC, Hutchison C, Cole T, et al. A randomized double-blind placebo-controlled trial to determine the effect of cranberry juice on decreasing the incidence of urinary symptoms and urinary tract infections in patients undergoing radiotherapy for cancer of the bladder or cervix. Clin Oncol (R Coll Radiol). 2012;24(2):31-38.

44. A. f. d. s. s. d. Aliments. Extension de l'allégation "contribue à diminuer la fixation de certaines bactéries E. coli sur les parois des voies urinaires". [Extension of attachment "Help to decrease adhesion of E.Coli to the bladder epithelium"]. Afssa-Saisine. 2007;2006-SA-0256.

45. Campbell G, Pickles T, D’Yachova Y. A randomized trial of cranberry versus apple juice in the management of urinary symptoms during external beam radiation therapy for prostate cancer. Clin Oncol ( $R$ Coll Radiol). 2003;15(6):322-328.

46. Soares S, Vitorino R, Osório H, et al. Reactivity of human salivary proteins families toward food polyphenols. J Agric Food Chem. 2011; 59(10):5535-5547.
Cancer Management and Research

\section{Publish your work in this journal}

Cancer Management and Research is an international, peer-reviewed open access journal focusing on cancer research and the optimal use of preventative and integrated treatment interventions to achieve improved outcomes, enhanced survival and quality of life for the cancer patient. The journal welcomes original research, clinical \& epidemiological

\section{Dovepress}

studies, reviews \& evaluations, guidelines, expert opinion \& commentary, case reports \& extended reports. The manuscript management system is completely online and includes a very quick and fair peerreview system, which is all easy to use. Visit http://www.dovepress.com/ testimonials.php to read real quotes from published authors. 